\title{
"THEY'RE NOT JUST FOR FRIDAYS ANYMORE": MEDIA LITERACY, HISTORICAL INQUIRY, AND HOLLYWOOD FILMS
}

\author{
Charles Elfer \\ Clayton State University \\ Scott L. Roberts \\ Central Michigan University \\ Brian Fahey \\ Forsyth County Schools
}

For generations, and perhaps since the inception of the motion picture industry, teachers of history have recognized the utility of incorporating Hollywood, or commercial, film productions into their classrooms as a visual stimulus. ${ }^{.}$Alan Marcus and Jeremy Stoddard, prolific scholars in the area of teaching with film, reported that more than two-thirds of the teacher population surveyed in a recent study claimed to use film in the classroom as frequently as once per week. ${ }^{2}$ Another notable contributor, William Russell, has echoed these findings and in a similar study found film in the history classroom to be ubiquitous, with $100 \%$ of participants reporting the use of film on a monthly basis. ${ }^{3}$ While anecdotal, teachers with whom we work regularly cite the use of film as a mainstay in their practice, a feature of the history classroom that certainly reflects our own memories as history students as well. Moreover, although these findings are far from exhaustive, they do underscore some important classroom realities. Advancements in the technological landscape of schooling have significantly impacted the degree of access to media and film for teachers and students. As illustrated through such commonly known platforms as YouTube or TeacherTube, the availability of full-length feature films and also an inestimable number of shorter clips and segments has proliferated. All of this is to say that teachers of history today have at their disposal an indispensable resource and are perhaps more likely than ever to incorporate the visual medium of film into their respective practices. Coupled with a media-oriented student population, the rationale for commercial film in the classroom has become especially relevant, as has the need for thoughtful considerations of usage.

${ }^{\text {I}}$ William B. Russell, Using Film in Social Studies (Lanham, MD: University Press of America, 2007).

${ }^{2}$ Alan S. Marcus and Jeremy D. Stoddard, "Tinsel Town as a Teacher: Hollywood Film in the High

School Classroom," The History Teacher 40 (2007): 309.

${ }^{3}$ William B. Russell, "The Reel History of the World: Teaching World History with Major Motion Pictures," Social Education 76 (2012): 22. 


\section{Challenges of Using Hollywood Films in the History Classroom}

Elsewhere we have noted that there are many challenges associated with using Hollywood films in the classroom; e.g., subject-matter controversy, film ratings, proprietary issues, availability, time, etc. ${ }^{4}$ The most important and well-documented critiques suggest that Hollywood productions often represent wholly unreliable sources of information, portrayals which may contain numerous inaccuracies or biases. Given the historical inaccuracies that tend to characterize commercial productions, simply viewing a given film often limits students' opportunities to develop an informed understanding of the topic under study. Teachers and students must understand the value and significance of engaging in a thoughtful and rigorous investigation of embedded topics. The absence of a structured activity, interpretive guide, or rationale for use potentially creates an environment where students are arguably just watching movies, which is rightfully frowned upon by administrators and parents alike. ${ }^{5}$ In this article, we outline two structured approaches to using film in the classroom, each of which seek to develop inquiry and media literacy skills in students of history by moving beyond the passive viewership that sometimes accompanies the Friday afternoon classroom cinema.

\section{Hollywood Films, Visual and Media Literacy, and Inquiry}

Despite the challenges of using commercial film productions in the classroom, the rewards are potentially great. In particular, the value of Hollywood feature films to promote literacy has been noted by researchers and teacher educators. In keeping with the professional literature linking visual and media literacy (VML) to the K-12 history/social studies classroom, scholars have paid special attention to the unique capacity of film to help students visualize events and concepts, develop personal connections to characters and events, sharpen analytical and interpretive skills, understand controversial issues, and, of course, more thoroughly investigate subject

\footnotetext{
${ }^{4}$ Scott L. Roberts and Charles J. Elfer, "Hollywood or History? Inquiring About U.S. Slavery Through Film," in Cinematic Social Studies, eds., William Russell and Stuart Waters (Charlotte, NC: Information Age Publishing, 2017).

${ }^{5}$ See Jeremy D. Stoddard and Allan S. Marcus, "More Than Just Showing What Happened: Exploring the Potential of Teaching with Film," The High School Journal 93 (2010): 83-90; Peter S. Taylor, "Watch and Learn, Kids: Why are Hollywood Films Taking Over High School Math, History, and Even Geography Class?," Maclean's 123 (2010): 57.
} 
area content. ${ }^{6}$ Visual literacy can be defined as "a set of abilities that enables an individual to effectively find, interpret, evaluate, use, and create images and visual media." Similarly, media literacy consists of "a series of communication competencies, including the ability to access, analyze, evaluate, and communicate information in a variety of forms, including print and non-print messages [emphasis added]." ${ }^{8}$ More specifically, as noted by Stein and Prewett, media literacy translates to the history/social studies classroom where it serves to "hone students' abilities to evaluate media as evidentiary sources, to identify bias in mediations for constructions of history and society, to understand how media frame issues, to separate fact from opinion, and to build analytical and reasoning skills." " In many ways, the existing scholarship on VML informs the purposeful use of film in the related domains of history and social studies education.

The benefits of combining VML and Hollywood films in the pursuit of empowering students to "adequately read media messages" and "navigate new literacy practices" are numerous. ${ }^{10}$ Due to the large number of historically-focused commercial films, educators and researchers in social studies and history education have shown particular interest and have offered various approaches to incorporate feature films into the K-12 classroom. ${ }^{11}$ Although many of these contributions do not directly reference the tenants or formal definitions of VML, they do closely parallel the central themes of

${ }^{6}$ See Marcus and Stoddard, "Tinsel Town as a Teacher: Hollywood Film in the High School Classroom," 309; Alan S. Marcus, Scott A. Metzger, Richard J. Paxton, and Jeremy D. Stoddard, Teaching History with Film: Strategies for Secondary Social Studies (New York: Routledge, 2010); Karl A. Matz and Lori L. Pingatore, "Reel to Real: Teaching the Twentieth Century with Classic Hollywood Films," Social Education 69 (2005): 189-192; Russell, Using Film in Social Studies; Sam Wineberg, Susan Mosborg, and Dan Porat, "What Can Forest Gump Tell Us About Students' Historical Understanding?," Social Education 65 (January/February 2001): 55-58.

${ }^{7}$ See the Association of College and Research Libraries, "ACRL Visual Literacy Competency Standards for Higher Education," http://www.ala.org/acrl/standards/visualliteracy.

${ }^{8}$ See the National Association for Media Literacy Education, "Media Literacy Defined," https://namle.net/ publications/media-literacy-definitions/.

'Laura Stein and Anita Prewett, "Media Literacy Education in Social Studies: Teacher Perception and Curricular Challenges,” Teacher Education Quarterly 36 (2009): 132.

\footnotetext{
${ }^{10}$ Jesse S. Gainer, "Critical Media Literacy in Middle School: Exploring the Politics of Representation," Journal of Adolescent and Adult Literacy 53 (2010): 364.

${ }^{11}$ Excellent examples include Marcus and Stoddard, "Tinsel Town as a Teacher: Hollywood Film in the High School Classroom"; Marcus, Metzger, Paxton, and Stoddard, Teaching History with Film; Matz and Pingatore, "Reel to Real," 189-192; Russell, Using Film in Social Studies; Wineberg, Mosborg, and Porat, "What Can Forest Gump Tell Us About Students' Historical Understanding?," 55-58.
} 
analysis, evaluation, and communication. ${ }^{12}$ Perhaps most importantly, each offers to the practitioners new approaches and rationales for incorporating media literacy skills into their existing instructional repertoires. ${ }^{13}$

Though relatively few in number, there is a small selection of scholarly articles explicitly linking the platform of visual and media literacy to the social studies and to history education, where Youngbauer along with Stein and Prewett represent two recent contributions. ${ }^{14}$ Stein and Prewett offer results from a survey of teachers' perceptions of media literacy and underscore the challenges of incorporating media literacy into the history/social studies classroom while offering solutions to assist field-based K-12 teachers. They found that $61 \%$ of teachers claimed to have had "some prior experience of teaching about media" and that over $70 \%$ recognized the importance of media literacy. At the same time, however, many respondents lacked confidence in their own abilities to analyze media and fewer than half felt comfortable teaching media literacy in their classrooms. Stein and Prewett attribute the results largely to teacher training and pay special attention to the lack of practitioner knowledge regarding state-level media literacy standards and the potential connections to the social studies. Interestingly, while the authors point out that teachers were motivated to understand media literacy education as a way to "prepare students for citizenship," they revealed that the depth of those connections was often rather shallow. Teachers did not, for example, mention media literacy components such as "protecting students from harmful media," promoting "health and development," or “enhance[ing] students' appreciation

\footnotetext{
${ }^{12}$ See the National Association for Media Literacy, "Media Literacy Defined."
}

\begin{abstract}
${ }^{13}$ See Vincent W. Youngbauer, "Application of Media Literacy and Cultural Studies in K-12 Social Studies Curricula," The Social Studies 104 (2013): 183-189. While arguably uniquely suited to such approaches, history and social studies teachers are certainly not the sole proprietors of film in the classroom and there are examples of the integration of VML and film in other disciplines. Gainer, for instance, describes how a teacher used the film "Dangerous Minds" in a critical literacy afterschool program to identify Hollywood stereotypes. Scheibe describes how the cartoon "Antz" was used to teach 100 students about insects in an elementary science classroom. After spending two weeks learning about the topic in their science classes, students in Scheibe's study compared what they learned to the depiction of ants and other insects in the film. After viewing the film, students had a chance to evaluate portrayals and to discuss any misrepresentations that they may have detected. An analysis of why filmmakers might represent ants in the ways that they did was also a subject of discussion. Scheibe found that based on this media literacy activity, students not only remembered the required content about ants six months later, but that the exercise also helped to build "critical thinking, communication, and technology skills," which helped students gain an "appreciation for multiple perspectives." Regardless of the field of study, then, the purposeful use of film in the classroom holds great value, particularly where students and teachers identify analysis, communication, and evaluation as desired ends. See Cynthia C. Scheibe, "A Deeper Sense of Literacy: Curriculum-Driven Approaches to Media Literacy in the K-12 Classroom," American Behavioral Scientist 40 (2004): 61.
\end{abstract}

${ }^{14}$ Stein and Prewett, "Media Literacy Education in Social Studies," 131-148; Youngbauer, "Application of Media Literacy and Cultural Studies in K-12 Social Studies Curricula," 184-187. 
of the media arts." Based on their findings, Stein and Prewett suggest offering teachers better access to primary media, to materials that show teachers the integration of media literacy across the curriculum, and to more and better teacher training. ${ }^{15}$

Concerned that researchers were focusing too heavily on movies as media literacy tools, Youngbauer's recent contribution to the field provides a "four-pronged approach to media literacy in the social studies," which he believes allows teachers to aid students in the analysis of all media, including commercial Hollywood films. Youngbauer argues that in social studies classes students should be taught to view media through historical, empirical, interpretive, and critical perspectives. The historical element requires students to have an understanding about both the evolution of media in the United States and how to determine the historical accuracy of films which treat historical topics on scales large and small. The empirical approach helps students to recognize "when bias is present, why it exists, and how it impacts our understanding of media ...." Elements of the interpretive approach include helping students analyze and assess the ways in which media texts are created. This could include historical media such as textbooks, historic sites, and historic markers. In turn, students should be given the opportunity to develop their own media text in an effort to understand how it is that historical events can be interpreted so differently by different individuals. Finally, critical media literacy "encourages students to consider why a message was sent and where it came from."16 Given the parallel goals of VML and contemporary research in history and social studies education, we anticipate that the complimentary nature of the two fields will become all the more pronounced in the coming years as scholars and practitioners recognize the potential that a merging of parallel conversations and research might hold for contemporary classrooms.

\section{Rationale for Visual-Based Learning}

Based on the relevant literature and the general limitations of viewing commercial films in the classroom, as well as a limited number of publications offering teachers and teacher educators specific lesson and unit ideas for using film in the history and social studies classroom, we sought to develop structured lesson ideas based upon this need. ${ }^{17}$ Given our background in history and social studies education, we collaboratively sought to find ways to combine the use of film with other sources and materials in an effort to

${ }^{15}$ Stein and Prewett, "Media Literacy Education in Social Studies," 138-143.

\footnotetext{
${ }^{16}$ Youngbauer, "Application of Media Literacy and Cultural Studies in K-12 Social Studies Curricula," 184-187.
}

${ }^{17}$ Marcus and Stoddard, "Tinsel Town as a Teacher: Hollywood Film in the High School Classroom"; Russell, Using Film in Social Studies; Stein and Prewett, "Media Literacy Education in Social Studies." 
help students develop a more sophisticated and evidence-based understanding of historical events. Simultaneously, we worked to foster analytic skills in young learners, a theme which has recently become a more standardized and mainstream focus through academic standards and frameworks for history and social studies education, such as those found in the Common Core Curriculum (e.g., CCSS.ELA-LITERACY.RH.6-8.7: Integrate visual information with other information in print and digital texts) and the $\mathrm{C} 3$ Framework produced by the National Council for the Social Studies, or NCSS (e.g., D3.3.3-5: Identify evidence that draws information from multiple sources in response to compelling questions). ${ }^{18}$ Lastly, it is worthy of note that these efforts mesh well with the national appeal from NCSS to promote media literacy within the social studies. ${ }^{19}$

In turn, the work of Stein and Prewett, Scheibe, and Youngbauer provided us with a sort of framework for incorporating the themes of visual and media literacy into a series of historical analysis exercises, specifically the classroom use of commercial film. It should be noted that while the experiences that background this present contribution are tied most directly to a history and social studies perspective, the concepts and procedures discussed can be used in most disciplines for analyzing visual $/$ media sources. As noted above, the core themes of analysis, evaluation, and communication are not wedded to a particular discipline, but are instead literacy objectives for all students and, in fact, critical measures of educational attainment across a variety of fields.

\section{Procedures}

The proceeding sections outline two structured approaches for incorporating Hollywood film into the history classroom. In the lines below, we provide a description of two strategies, accompanied by step-by-step lesson plans which are scaffolded across grades 5,8 , and 11 to reach a wide range of potential audiences and purposes. These lessons were collaboratively developed by a small team of classroom teachers and teacher educators with classroom experiences spanning the middle, secondary, and post-secondary levels. Charles Elfer has taught general and advanced placement

\footnotetext{
${ }^{18}$ See the National Council for the Social Studies, "The College, Career, and Civic Life (C3) Framework for Social Studies State Standards: Guidance for Enhancing the Rigor of K-12 Civics, Economics, Geography, and History," http://www.socialstudies.org/system/files/c3/C3-Framework-for-SocialStudies.pdf; National Governors Association for Best Practices, Council for Chief State School Officers, "Common Core Standards for English Language Arts \& Literacy in History/Social Studies, Science, and Technical Subjects," http://www.socialstudies.org/system/files/publications/se/6501/650109.html; Scott L. Roberts, "Effectively Using Social Studies Textbooks in Historical Inquiry," Social Studies Research and Practice 9 (Spring 2014): 119-128.
}

${ }^{19}$ National Council for the Social Studies, "Media Literacy: A Position Statement," Social Education 37 (2009): 187-189. 
courses in world and United States history and geography at the secondary and postsecondary levels and currently serves as an assistant professor of history education. Scott Roberts taught eighth-grade social studies for several years before serving as a district-level curriculum specialist and Teaching American History Grant Director. He is presently an assistant professor of elementary social studies education. Brian Fahey currently serves as an Advanced Placement United States history teacher at a large public high school. A recent field visit to the Gettysburg battlefield and subsequent conversations regarding practice gave rise to the lesson ideas described in this article.

The lesson ideas outlined here can be locally adapted and modified by elementary, middle, and high school teachers as needed. As detailed above, with the intent of bridging themes in VML and the aims of the history/social studies classroom, the plans also draw on Youngbauer's approach for applying media literacy, and an effort is made to highlight those elements within the plans and lesson procedures. The film Gettysburg (1993) was chosen as the visual medium for the analysis in light of the perennial significance of the American Civil War in United States history and, to a lesser extent, the timeliness of the recent sesquicentennial commemorations of the conflict. Readers will note that there are many alternative films about the war that could be used in this type of analysis, not to mention other historical personas and events. ${ }^{20}$ While these lessons were written for history and social studies teachers, English and language arts teachers might also find these ideas useful as the film is based upon a work of historical fiction, specifically The Killer Angels. ${ }^{21}$ And lastly, although the topic and a number of sources sampled are the same in each of the lessons provided, the lessons themselves may be used in tandem or independently at the user's discretion. Our purpose in sharing these experiences is simply to offer a structured platform for practitioners that might guide historical inquiry through the medium of film in ways that more general discussions often do not. That said, while endeavoring to provide ample detail and explanation, the discussion is necessarily abbreviated and selective given the constraints of space and time. ${ }^{22}$

\footnotetext{
${ }^{20}$ See William B. Russell, Civil War Films for Teachers and Historians (Lanham, MD: University Press of America, 2007).

${ }^{21}$ Michael Shaara, The Killer Angels (New York: Crown Publishers, 1974).

${ }^{22}$ For additional illustrations of the "Hollywood or History?" strategy and instruction platform, see Scott L. Roberts, "Effectively Using Social Studies Textbooks in Historical Inquiry;" Charles J. Elfer and Scott L. Roberts, "Applying Disciplinary Concepts and Tools: Fostering Student Inquiries Through "The Cultural Approach,"” The Leader 29 (Fall 2015): 25-30.
} 


\section{Hollywood or History? Little Round Top}

The first lesson that we created is rooted in a strategy developed by Scott Roberts when he was a classroom teacher and is referred to as "Hollywood or History?" Based upon student evaluations of evidence from multiple sources in a document collection, this strategy asks students to determine whether or not a movie clip about a particular social studies topic is $100 \%$ History (all fact), $100 \%$ Hollywood (all fiction) or somewhere in between. ${ }^{23}$ The method offers students a chance to critically analyze a film, or part of a film, by using primary sources (e.g., letters, photographs, newspapers, etc.), and secondary sources (e.g., textbooks, novels, biographies, etc.) in developing their own positions regarding accuracy. In this lesson, a clip from the film Gettysburg, concerning the actions of Joshua Lawrence Chamberlain during the skirmish at "Little Round Top," is compared with an account from a collection of primary sources and a collection of secondary sources. ${ }^{24}$

The Hollywood vs. History? lesson concerning the Battle of Gettysburg is broken up into eight steps. ${ }^{25}$ The general procedure for this historical thinking activity reads as follows:

- Step 1: Start with a whole class, roundtable, or group discussion - work to spark some ideas about how social elements like movies, video games, or books that focus on historical topics can shape our understanding of people, places, and events. This discussion touches on the historical and empirical dimensions of Youngbauer's approach to historical thinking and media literacy. As Youngbauer states, it is important that students are able to gain an understanding of the historical background of a topic. However, in this step, this should not only be a discussion about ways to judge the historical accuracy through the media, but also about the empirical approach and how contemporary events and ideas change our interpretations of history. In this initial, open-ended stage of the lesson, students and teachers are invited informally to consider the ways in which historical (in)accuracy is present in film productions and the historical contexts in which films are produced. Age-level and development will impact the degree of teacher involvement required. We recommend a consideration of Birth of a Nation (1915), Gone with the Wind (1939), and Ken Burns' The Civil War (1990/2015) as potentially useful points of contrast and comparison. For other audiences, more popular samples that connect to existing student interests and knowledge would

\footnotetext{
${ }^{23}$ Ibid.
}

${ }^{24}$ Referenced movie clips are available through YouTube.

\footnotetext{
${ }^{25}$ For the complete lesson plan visit: https://culturalapproach.columbusstate.edu/hollywood-or-history/.
} 
be sufficient to underscore the concept, even if not directly connected to the historical topic under consideration here.

- Step 2: Step 2 is intended to ensure that students have adequate background specific to the themes and topics within the film. Deliver a 15-20 minute minilecture on the Battle of Gettysburg, reminding students about its importance in the Civil War and how it was seen as a turning point in the overall conflict (this should have been taught in a prior lesson and will vary in scale and detail by grade level, etc.). Explain to students that they are going to investigate an event that some believe to be the "Turning point of the turning point;" that is, Gettysburg was the turning point in the war (if not the nation's history) and this particular military action (Little Round Top) was arguably central to a Union victory at Gettysburg. Ensuring that students have a solid background knowledge of the event is part of the historical approach to media literacy. The lesson hinges on the development of content knowledge, which will ultimately support students in effectively making sense of the film and the degree of historical accuracy. We should also note that with some reworking, Steps 1 and 2 could be effectively combined, particularly where teachers endeavor to introduce other historically themed media such as those highlighted in Step 1.

- Step 3: Explain to students that Hollywood has tried to capture the battle visually in a movie called Gettysburg (1993) which is based on a work of historical fiction titled The Killer Angels (1987). Introduce the Hollywood or History? graphic organizer provided and explain to students that they can use this document to record information during the movie clip and while analyzing the sources encountered in the document collection. This step addresses the conceptual framework offered by Youngbauer referenced above. More explicitly, Step 3 and the instructional supports provided allow students to analyze each of the sources independently and to keep track of those evaluations as they are produced. Students are invited to critically evaluate the sources encountered and to explore the related questions of origin and purpose.

- Step 4: Display clip of the movie Gettysburg.

- Step 5: Have students analyze their primary source (choose one from document set provided based upon your students' ability level) and secondary source (choose one from document set based on your students' ability level). Using these sources mirrors the interpretive framework as students must make meaning of the multiple sources and how they relate to the film.

- Step 6: Students individually conclude whether or not the Battle for Little Round Top scene is Hollywood or History by writing an essay citing evidence from each source that they have encountered. This step requires that students use critical media literacy skills to consider the purpose(s) of the film and whether or not the producers meant for the film to be digested as history, entertainment, or a mixture of both. 
- Step 7: Use a "Line of Contention" to allow students to share their thoughts as a whole class. Draw a line on the board to demonstrate the continuum of perspectives. At one end of the line, write " $100 \%$ History" to indicate to students that those who stand there are making the claim that the movie clip is $100 \%$ accurate and factual. At the other end of the line, write " $100 \%$ Hollywood." If students stand next to this part of the line, they are making the claim that there is nothing factual about the scene they have watched. Allow students to stand at any point of the line they wish (i.e., $25 \%$ History, $75 \%$ Hollywood, etc.). After providing students with an opportunity to take their position, call on volunteers to share their perspectives and rationales. Step 7 requires student interpretation and sets the stage for the creation of media text in Step 8 .

- Step 8: Have students write a script offering a more accurate account of the Battle of Little Round Top based upon the movie Gettysburg and the supporting documents. You might elect to incorporate a program such as iMovie, create a new film clip, and possibly upload this updated scene to YouTube or to a class website. This step again draws on students' interpretive skills as an avenue to media literacy as they are given an opportunity to create their own media text. According to Youngbauer, this type of activity can help students to better understand "other media texts" as they move between "reflection and production." 26

\section{A Structured Academic Controversy: Chamberlain-A Political or Social Hero?}

The second lesson that we developed is based upon an inquiry strategy widely known as the "Structured Academic Controversy," or SAC. This strategy is frequently utilized by professional educators in the social studies and in history education and allows students to analyze multiple sources, including visual media. As before, the method described below works to incorporate each dimension of Youngbauer's fourpronged approach as a way of bridging historical thinking and visual media literacy. Students participating in the exercise are asked to use primary and secondary sources as evidence in highly structured debate stemming from an initial, sparking question. Much like the Hollywood or History? activity, the lesson invites students to analyze a movie clip from the film Gettysburg as well as other primary and secondary source materials. Whereas we designed the Little Round Top exercise around a particular historical moment, the $\mathrm{SAC}$ requires that students develop positions about the memory and character of a particular historical figure, Joshua Lawrence Chamberlain, through time. In brief, Chamberlain became and has remained a very vibrant Union figure and has reached near celebrity status in both fictional and historical works. Because

\footnotetext{
${ }^{26}$ Youngbauer, "Application of Media Literacy and Cultural Studies in K-12 Social Studies Curricula," 187.
} 
Chamberlain went on to accomplish much after the war, locating the origins of his legacy and heroism represents a suitable and interesting context for inquiry for students of history. After students complete their collaborative primary and secondary source evaluations, they will take part in a structured debate prompted by the following question that coincides well with Youngbauer's empirical and critical approaches:

Was Joshua Lawrence Chamberlain a political or social hero? Is Chamberlain viewed as a hero because his deeds led to a great military and political victory for the Union during the American Civil War? Or, did he become a hero due to the fact that his character and life story were so valued in $19^{\text {th }}$ century American society?

As the lesson plan details, this "debate" exercise is non-traditional, highly collaborative, and was designed in part to promote consensus through thoughtful deliberation. Through an analysis of primary and secondary source documents and the evaluation of the Little Round Top scenes in the film Gettysburg, students will have the opportunity to evaluate how and why the Chamberlain legacy has taken the shape that it has. In other words, students are asked to decide how the historical view of Chamberlain may have been impacted by the values of his time, and then to consider why this message about Chamberlain's heroism was "sent and where it came from." ${ }^{\text {"27 }}$ Note that despite the appearance of dichotomy in the initial prompt for the inquiry, the goal here is not to reinforce either/or thinking, but rather to encourage reasoning processes and a commitment to textual evidence. This structured academic controversy is broken up into seven steps: ${ }^{28}$

- Step 0: distribute GUIDESHEETS (all lesson materials available electronically at web address below) outlining for students the format and steps of the SACChamberlain: Political or Social Hero? Start with a brief, roundtable discussion based on questions that help to support students' understanding when it comes to the empirical and critical lenses of media literacy. Examples of these types of questions could include:

- What does it mean to be a hero in 2017 and who are some modern examples?

- Are ideas about heroism universal and how do media impact those ideas?

${ }^{27}$ Ibid.

${ }^{28} \mathrm{~A}$ fully articulated lesson plan, including document sets and handouts for grades 5,8 , and 11 , can be found at the following web address: https://culturalapproach.columbusstate.edu/a-political-or-socialhero/. 
0 Is there any evidence to suggest that our conceptions of heroism change over time and/or from one social group to the next?

- Step 1: Divide the class into groups with social and political camps as indicated in the lesson protocol. You may elect to create multiple debate pairs, rather than simply dividing the classroom in half. A good idea would be to have 3-4 members per camp, perhaps a total of 8 per group ( 3 debate pairs in a class of 24 students). In doing so, each team member will be responsible for a single text, thus ensuring that the position development portion of the exercise can be completed within the allotted time, and, importantly, that all students participate.

- Step 2: Allow students ample time to get situated with their groups and to understand the task at hand. Once members have relocated and settled in, display the clip of the movie Gettysburg. This clip will allow all students, regardless of the side of the argument that they have chosen/been assigned to, to gain a sense of the Battle of Little Round Top. Subsequently, students can refine their initial perceptions and reactions as new evidence is encountered. Including a film in this type of discussion further incorporates Youngbauer's historical, empirical, and critical approaches to using media literacy.

- Step 3: Following GUIDESHEET \#1, each group will have 30 minutes to read their assigned texts, view the necessary film clips, and craft 2-4 evidence-based position statements supporting their side of the argument. Remind students to refer to the texts (including film clips). In so doing, students must also evaluate the relative merits of each of the texts encountered (i.e., source, contextualize, etc.). Use GUIDESHEET \#2 to record positions.

- Step 4: Following GUIDESHEET \#1, each group will have approximately 10-15 minutes to deliver their initial position statements, roughly 5-7 minutes per side. NOTE: After each side presents the position statements, the opposing group must restate the arguments to the authors' satisfaction. Both sides should follow this process. GUIDESHEET \#2 can be used for record keeping.

- Step 5: Following GUIDESHEET \#1, groups must now work for approximately 30 minutes to build consensus. Both sides should temporarily abandon their allegiances to their original positions and work to find common ground with their peers. Collectively, students need to reconsider the evidence, determine which pieces are most credible and why, and ultimately reconsider the inquiry prompt. Several guiding questions are included in GUIDESHEET \#1 to assist students as they evaluate the documents, and the group must work to draft and record a statement of consensus, always drawing on the evidence available.

- Step 6: With the time remaining, bring the class back together for sharing of final consensus statements.

- Step 7: A final, summative assessment is required. Have students use a digital storytelling website such as VoiceThread to display their arguments concerning Chamberlain's heroism. Students should use a variety of sources including movie clips, images, and other primary and secondary source materials to support their 
claims. Following Youngbauer's interpretive approach for media literacy, students should be given the opportunity to create their own media in order to be able to better understand and to reflectively critique products made by others.

\section{Outcomes}

As noted above, we have used both the Hollywood or History? and the Chamberlain SAC in our own classrooms and with great success. Scott Roberts' students, as one example, noted their appreciation for Hollywood or History? lessons and some even created their own based upon Hollywood feature films that they saw with their parents. On one occasion, an eighth-grade student came into class with a fully completed Hollywood or History? graphic organizer based upon the inaccuracies found in the movie 300 (2006). As further indication of the appeal that these approaches might offer, we turned to our experiences as teacher educators. Midterm and post-course reviews of these sorts of lesson ideas are always highly rated by our students and often used in end-of-course lesson and unit plan assessments, not to mention in the field during supervisory visits. Many classroom teachers that have taken part in workshops and professional conference presentations have also praised the approach and installed these practices in their own classrooms. As one teacherparticipant noted:

Thank you so much for presenting yesterday, I had such a great time in your session and learned so much ... My wife is a fifth grade teacher and is currently finishing the Civil War. I could not stop going on and on about your presentation and the utilization of primary and secondary sources ... She has also fallen in love with the material and the information you provided.

Or, as another teacher wrote: "Hi, thanks so much for the presentation last Thursday. I thoroughly enjoyed it and gained insight into further lesson development using primary and secondary sources with films." While these illustrations are anecdotal, we believe that our experiences with media and source work do indicate something larger and are markers of the effectiveness and utility of the methods that we have described above. Given the success of the strategies highlighted here, we believe that the appetite for purposeful and engaging applications of film in the classroom, in particular the history classroom, is especially robust.

\section{Reflections and Insights}

We drafted this article with one primary goal in mind; that is, we wanted to attend to some of the gaps identified within the relevant literature to provide practitioners with structured strategies and field-tested lesson plans that integrate the themes of media 
literacy by effectively using the medium of Hollywood film in the classroom. While we hope that the suggestions for practice and experiences shared are useful to readers and find their way into classrooms, there is, of course, far more work to be done. The conversations addressing the pedagogical potential for the purposeful use of film in the history classroom are ones that will hopefully grow much louder and include more voices. Nonetheless, both lessons introduced above encourage students to "read visual and audiovisual messages, as well as text based ones," to appreciate "the techniques used to persuade and convey emotion," and to "communicate effectively through different media forms." ${ }^{29}$ At the very least, we estimate that the types of experiences outlined here represent a starting point that is closely related to the larger goals of history education and tangible enough to be of practical utility.

Significantly, and rooted again in the concept of visual media literacy, we reason that if readers endeavor to adapt the ideas presented above to their own purposes, and to develop and implement these and similar lesson ideas in their own classrooms, a greater number of students would ultimately have the opportunity to develop the skills needed to more adeptly "judge the credibility and accuracy of information" of virtually any source of information more critically, whether it be a popular motion picture themed around a historical topic or perhaps the onslaught of competing narratives one inevitably encounters in a presidential election year. ${ }^{30}$ Thus, inquiries developed around historically-themed films support the development of a range of literacy skills that enhance, but extend beyond the history classroom alone. ${ }^{31}$ As have others, we recognize that students must develop these types of skills at an early age and throughout the process of formal schooling. In sum, the essential habits of evaluation, analysis, and communication are equally requisite for historical understanding and effective participation in a democratic society.

\footnotetext{
${ }^{29}$ Scheibe, "A Deeper Sense of Literacy: Curriculum-Driven Approaches to Media Literacy in the K-12 Classroom," 61 .

${ }^{30}$ Ibid.
}

\footnotetext{
${ }^{31}$ See Keith C. Barton and Linda S. Levstik, Teaching History for the Common Good (Mahwah, NJ: Lawrence Erlbaum, 2004).
} 